\title{
RANKING TERRORIST NODES OF 9/11 NETWORK USING ANALYTICAL HIERARCHY PROCESS WITH SOCIAL NETWORK ANALYSIS
}

\author{
Pankaj Choudhary* \\ Email: pankaj_pcse13@diat.ac.in \\ Upasna Singh* \\ Email: upasnasingh@diat.ac.in \\ * Department of Computer Engineering \\ Defence Institute of Advanced Technology \\ Pune, India
}

\begin{abstract}
On September 11, 2001, United States witnessed one the most tragic terrorist attacks in history, well-known as 9/11 attack. Four coordinated suicide terrorist attacks on high profile U.S. landmarks were executed by Islamic terrorist group Al-Qaeda. Social Network Analysis (SNA) has been accepted worldwide to be the most promising method for investigating such type of terrorist attacks. In prior research, various centrality measures of SNA have been discussed for identifying key players and attaining terrorist target lists/ranking. Most of the times, these measures result in different rank ordering patterns and different set of key players. As a solution to this problem, Analytical Hierarchy Process (AHP) can be plugged in with SNA centrality measures for obtaining improved results with the essence of subjective or objective choices of the decision maker. In this paper, 9/11 terrorist network is analyzed using AHP with SNA centrality measures as decision criteria, to discover the overall rank ordering of 19 hijackers and their affiliates, involved in the attack. Further, sensitivity analysis is discussed to deal with changes in subjective judgements. The experimental results demonstrate that the combination of AHP with SNA centrality measures results in propitious rank ordering in considered terrorist network.
\end{abstract}

Keywords: 9/11 Terrorist Attack; Analytical Hierarchy Process (AHP); Social Network Analysis (SNA); Centrality Measures; Key Players; Ranking Terrorist Nodes, Terrorist Targeting.

\section{Introduction}


On the morning of Tuesday, September 11, 2001, whole world was shocked by one the most terrible terrorist attack over United States in history, known as 9/11 attack. 19 AlQaeda terrorists involved in the attack, hijacked four passenger airlines and coordinated suicide terrorist attacks on high profile U.S. landmarks (World Trade Center and the Pentagon).

After tragic event of 9/11 terrorist attack, various research communities based on counterterrorism attracted towards Social Network Analysis (SNA). SNA is a method based on network and graph theory for analyzing social relations in form of nodes (individuals, organizations, events etc.) and relation between them (i.e. friendship, kinship, conversation, money transection, co-workers etc.). In countering terrorism and crime, SNA has been well recognized in key-player identification, community detection, covert network analysis, dynamic network analysis, targeting and disruption of terrorist networks. Centrality measures in SNA [2] play major role in identifying the key players and rank ordering of terrorist nodes in such networks. During targeting process in terrorist networks, different centrality measures result in different set of key players and different patterns of rank ordering, which in effect make the targeting very difficult. Analytical Hierarchy Process (AHP) can be applied with these SNA centrality measures for improving the targeting with the core of decision maker's control over subjective or objective judgements.

\section{Literature Review}

Various measures of Centrality like Degree, Eigenvector, Betweenness and Closeness has been evolved over time for identifying key players or leaders in the social network [2].

By collecting publicly available information, Krebs [1], mapped the 9/11 terrorist network of 19 hijackers of Al-Qaeda and their affiliates and analyzed it using basic SNA centrality measures with the help of SNA tools. Our previous review article [3] focused on the role of SNA in Counter-Terrorism.

Saaty developed AHP [4], [5], [6] as a multiple attribute decision making technique to solve complex decision problems, with various criteria (attributes), alternatives and subjective choices of decision maker over them.

\section{Objectives}

In this paper, 9/11 terrorist network is investigated using AHP, plugged in with SNA centrality measures, in order to obtain the rank ordering of all 63 nodes (19 hijackers and their affiliates) involved in the attack and to identify the key players among them. Ranking based on AHP, might provide visions for targeting key players and disrupting the terrorist networks. Data used for 9/11 terrorist network is publically available based on Krebs's work [1]. 
ISAHP Article: A Style Guide for Paper Proposals To Be Submitted to the International Symposium on the Analytic Hierarchy Process 2016, London, U.K.

\section{Methodology}

Terrorist organizations/activities can be represented very well using SNA, as individual terrorist members as nodes and their relationships as edges often in the form of graph/network or adjacency matrix. Social Network Graph of 9/11 Network is shown in Figure 1.

For finding key players and ranking of nodes in the network, various centrality measures are applied. In our study, we used Degree, Eigenvector, In-degree, Out-degree, Closeness and Betweenness for the same. Normalized values of these centrality measures for all 63 nodes of 9/11 network are calculated and presented in Figure 2.

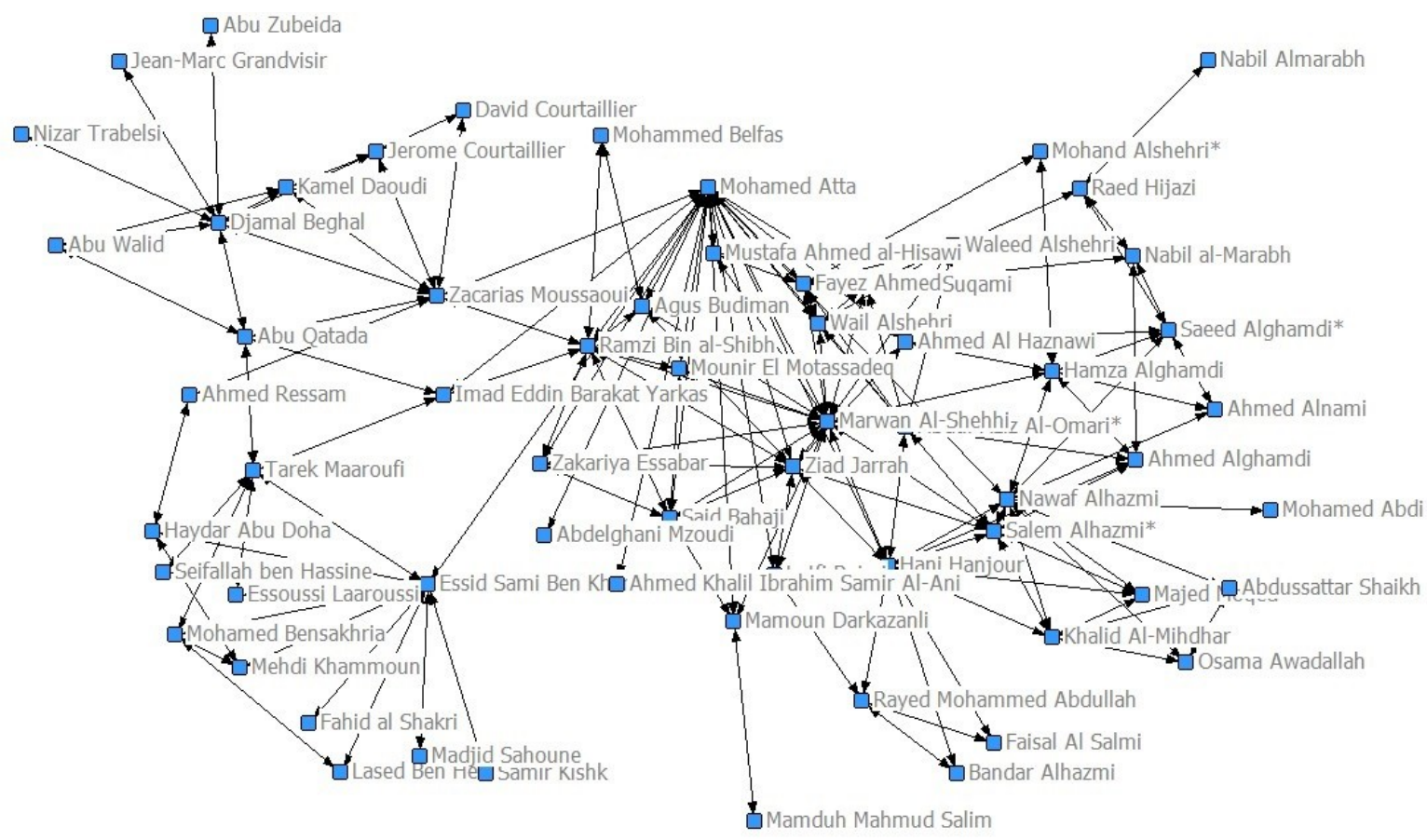

Figure 1: Social Network Graph of 9/11 Network 
ISAHP Article: A Style Guide for Paper Proposals To Be Submitted to the International Symposium on the Analytic Hierarchy Process 2016, London, U.K.

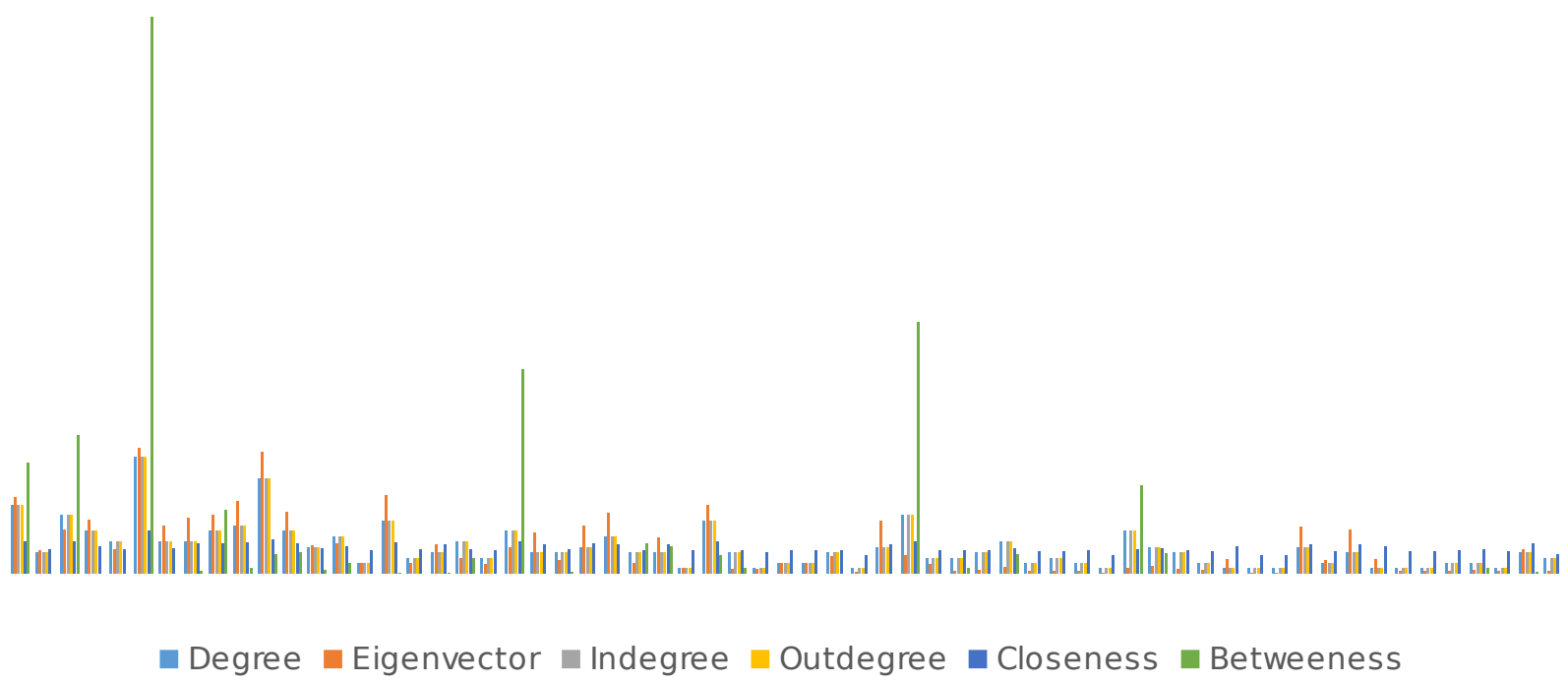

Figure 2: Normalized Centrality Measures for 9/11 Network

For obtaining the overall ranking of terrorist nodes, AHP is formulated as a multiple attribute decision making technique. AHP decision hierarchy for proposed method is shown in Figure 3. Above considered six centrality measures are framed as our decision criteria and all terrorist nodes of 9/11 network are taken as alternatives.

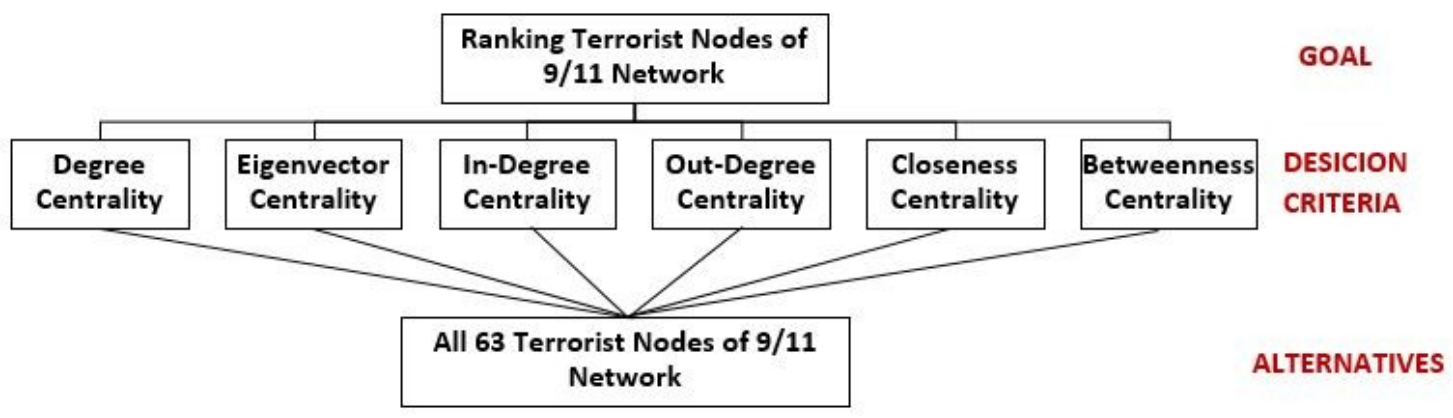

Figure 3: AHP Decision Hierarchy for 9/11 Network

\section{Data/Model Analysis}

Criteria weights are evaluated using Saaty's nine point scale [5] [6] for pairwise comparison and subjective choices of the decision maker. Based on our subjective choices and various research articles, discussing the importance of centrality measures [7] pairwise comparison matrix (shown in Table 1) is produced for ranking 9/11 terrorist nodes. 
ISAHP Article: A Style Guide for Paper Proposals To Be Submitted to the International Symposium on the Analytic Hierarchy Process 2016, London, U.K.

Table 1: Pairwise Comparison Matrix for Criteria

\begin{tabular}{|c|c|c|c|c|c|c|}
\hline & Degree & Eigenvector & $\begin{array}{c}\text { In- } \\
\text { Degree }\end{array}$ & $\begin{array}{c}\text { Out- } \\
\text { Degree }\end{array}$ & Closeness & Betweenness \\
\hline Degree & 1 & $1 / 4$ & 2 & 2 & $1 / 2$ & $1 / 4$ \\
\hline Eigenvector & 4 & 1 & 4 & 4 & 2 & $1 / 2$ \\
\hline In-Degree & $1 / 2$ & $1 / 4$ & 1 & 1 & $1 / 3$ & $1 / 4$ \\
\hline Out-Degree & $1 / 2$ & $1 / 4$ & 1 & 1 & $1 / 3$ & $1 / 4$ \\
\hline Closeness & 2 & $1 / 2$ & 3 & 3 & 1 & $1 / 2$ \\
\hline Betweenness & 4 & 2 & 4 & 4 & 2 & 1 \\
\hline
\end{tabular}

For dealing with the inconsistencies of pairwise matrix, consistency ratio is evaluated. We found that our pairwise comparison matrix is consistent, as the value of consistency ratio, CR is 0.021 (i.e. less than 0.1). Using eigenvector method, criteria weights are calculated as shown in Table 2 .

Table 2: Decision Criteria Weights

\begin{tabular}{|c|c|}
\hline Criteria & Criteria Weights \\
\hline Degree & 0.094 \\
\hline Eigenvector & 0.269 \\
\hline In-Degree & 0.062 \\
\hline Out-Degree & 0.062 \\
\hline Closeness & 0.169 \\
\hline Betweenness & 0.341 \\
\hline
\end{tabular}

In order to evaluate the final ranking of $9 / 11$ terrorist nodes, criteria weights $(6 \mathrm{X} 1$ matrix, in Table 2 ) is aggregated with normalized centrality values of each terrorist nodes (as 63 X 6 matrix), using simple matrix multiplication.

The final AHP score values ( $63 \times 1$ matrix) of all terrorist nodes of 63/11 network can be visualized as in Figure 4. 
ISAHP Article: A Style Guide for Paper Proposals To Be Submitted to the International Symposium on the Analytic Hierarchy Process 2016, London, U.K.

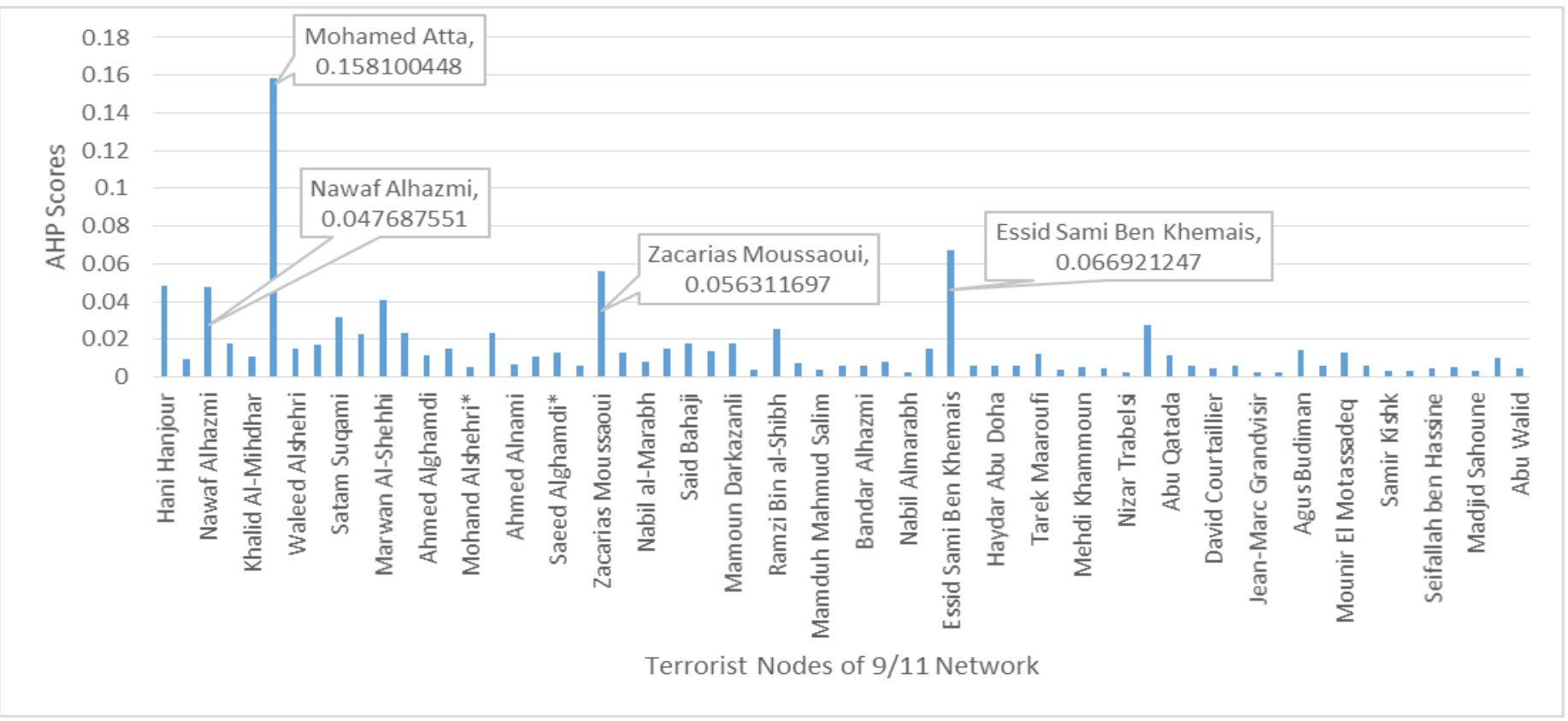

Figure 4: AHP Scores of Terrorist Nodes for 9/11 Network

Comparison of ranking of top 10 nodes based on centrality measures and our proposed AHP approach is shown in Table 3.

Table 3: Comparison of Ranking of Nodes based on Centrality Measures and Proposed AHP Approach

\begin{tabular}{|c|c|c|c|c|c|}
\hline $\begin{array}{c}\text { Node } \\
\text { Ranking }\end{array}$ & Degree & Eigenvector & Closeness & Betweeness & AHP Score \\
\hline 1 & Mohamed Atta & Mohamed Atta & Mohamed Atta & Mohamed Atta & Mohamed Atta \\
\hline 2 & $\begin{array}{c}\text { Marwan Al- } \\
\text { Shehhi }\end{array}$ & Marwan Al-Shehhi & Marwan Al-Shehhi & $\begin{array}{c}\text { Essid Sami Ben } \\
\text { Khemais }\end{array}$ & $\begin{array}{c}\text { Essid Sami Ben } \\
\text { Khemais }\end{array}$ \\
\hline 3 & Hani Hanjour & Ziad Jarrah & Hani Hanjour & $\begin{array}{c}\text { Zacarias } \\
\text { Moussaoui }\end{array}$ & $\begin{array}{c}\text { Zacarias } \\
\text { Moussaoui }\end{array}$ \\
\hline 4 & Nawaf Alhazmi & Hani Hanjour & Nawaf Alhazmi & Nawaf Alhazmi & Hani Hanjour \\
\hline 5 & $\begin{array}{c}\text { Essid Sami Ben } \\
\text { Khemais }\end{array}$ & $\begin{array}{c}\text { Abdul Aziz Al- } \\
\text { Omari* }\end{array}$ & Zacarias Moussaoui & Hani Hanjour & Nawaf Alhazmi \\
\hline 6 & Ziad Jarrah & Ramzi Bin al-Shibh & Ramzi Bin al-Shibh & Djamal Beghal & Marwan Al- \\
\hline 7 & $\begin{array}{c}\text { Ramzi Bin al- } \\
\text { Shibh }\end{array}$ & Fayez Ahmed & $\begin{array}{c}\text { Essid Sami Ben } \\
\text { Khemais }\end{array}$ \\
\hline 8 & $\begin{array}{c}\text { Abdul Aziz Al- } \\
\text { Omari* }\end{array}$ & Said Bahaji & $\begin{array}{c}\text { Abdul Aziz Al- } \\
\text { Omari* }\end{array}$ & Satam Suqami & Satam Suqami \\
\hline 9 & Salem Alhazmi* & Satam Suqami & Ziad Jarrah & Mamoun & Djamal Beghal \\
\hline 10 & Satam Suqami & Wail Alshehri & Satam Suqami & Fayez Ahmed & Ziad Jarrah \\
\hline
\end{tabular}


ISAHP Article: A Style Guide for Paper Proposals To Be Submitted to the International Symposium on the Analytic Hierarchy Process 2016, London, U.K.

Ranking based on AHP as Social network graph (node size ordered by AHP score) of 9/11 network is shown in the Figure 5,

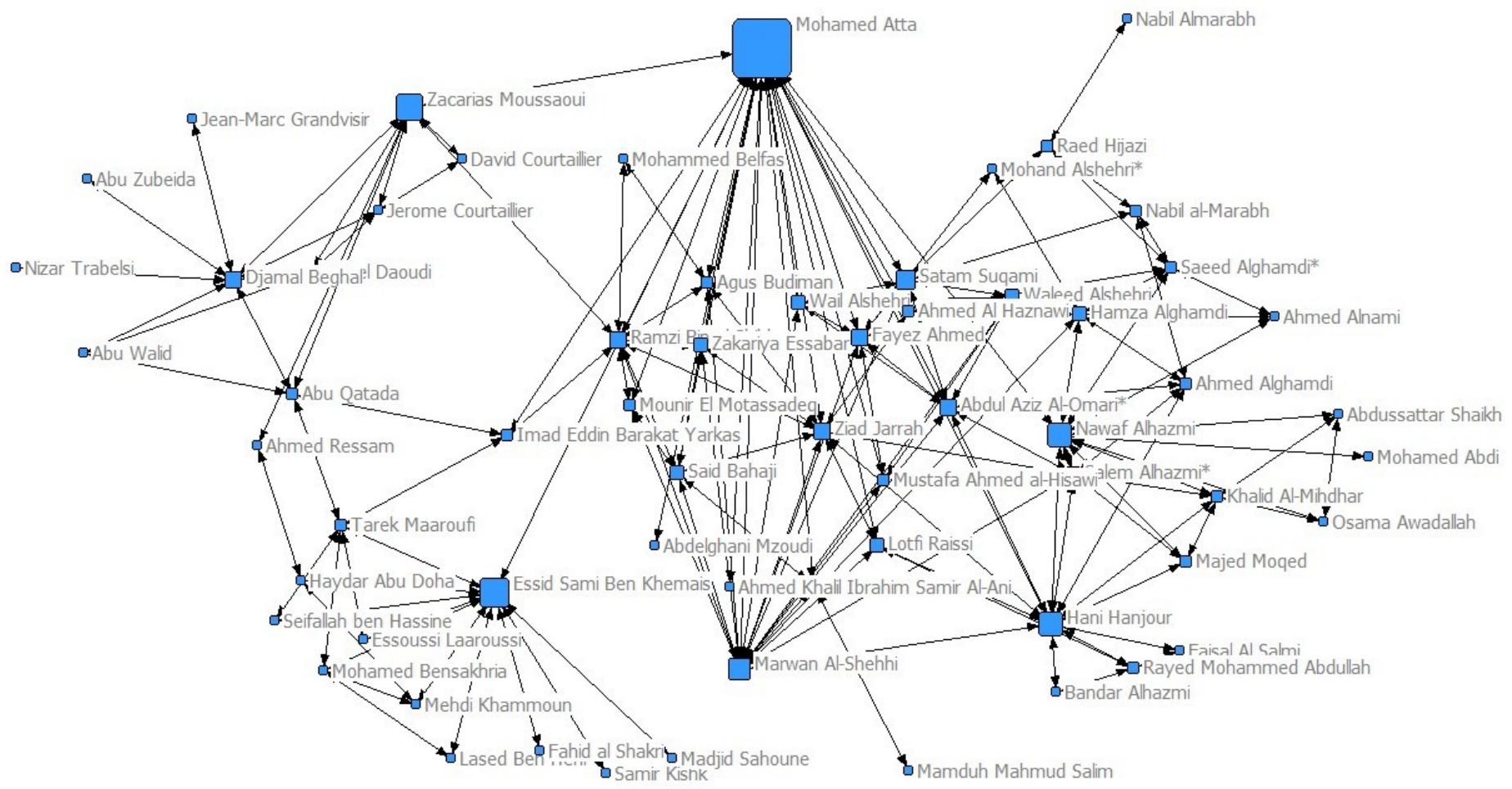

Figure 5: Social Network Visualization of Final Rankings using AHP for 9/11 Network

\section{Result and Discussion}

Based on this study, it is found that Mohamed Atta, with highest AHP score is the most important individual, as he emerged as local leader handling the entire operation. Other key players in top 5 ranking are Essid Sami Ben Khemais, Zacarias Moussaoui, Hani Hanjour, Nawaf Alhazmi. The result represents the overall ranking of terrorist nodes based on the subjective judgments over considered six centrality measures as our decision criteria.

Many times these rankings are exposed to change with the variation in subjective judgements at the time of pairwise comparison of decision criteria. Sensitivity analysis can be framed using controlled trial and error method to evaluate the effect of rank changing and finding out the most sensitive criteria, affecting the ranking most.

For 9/11 Terrorist network, we performed the sensitivity analysis by linearly changing (increasing and decreasing) weights of all six criteria, and then observing the change in the rank of all nodes each time. Changes in top 10 node ranks with increase and decrease criteria weights are shown in Figure 6 and 7 respectively. 
ISAHP Article: A Style Guide for Paper Proposals To Be Submitted to the International Symposium on the Analytic Hierarchy Process 2016, London, U.K.
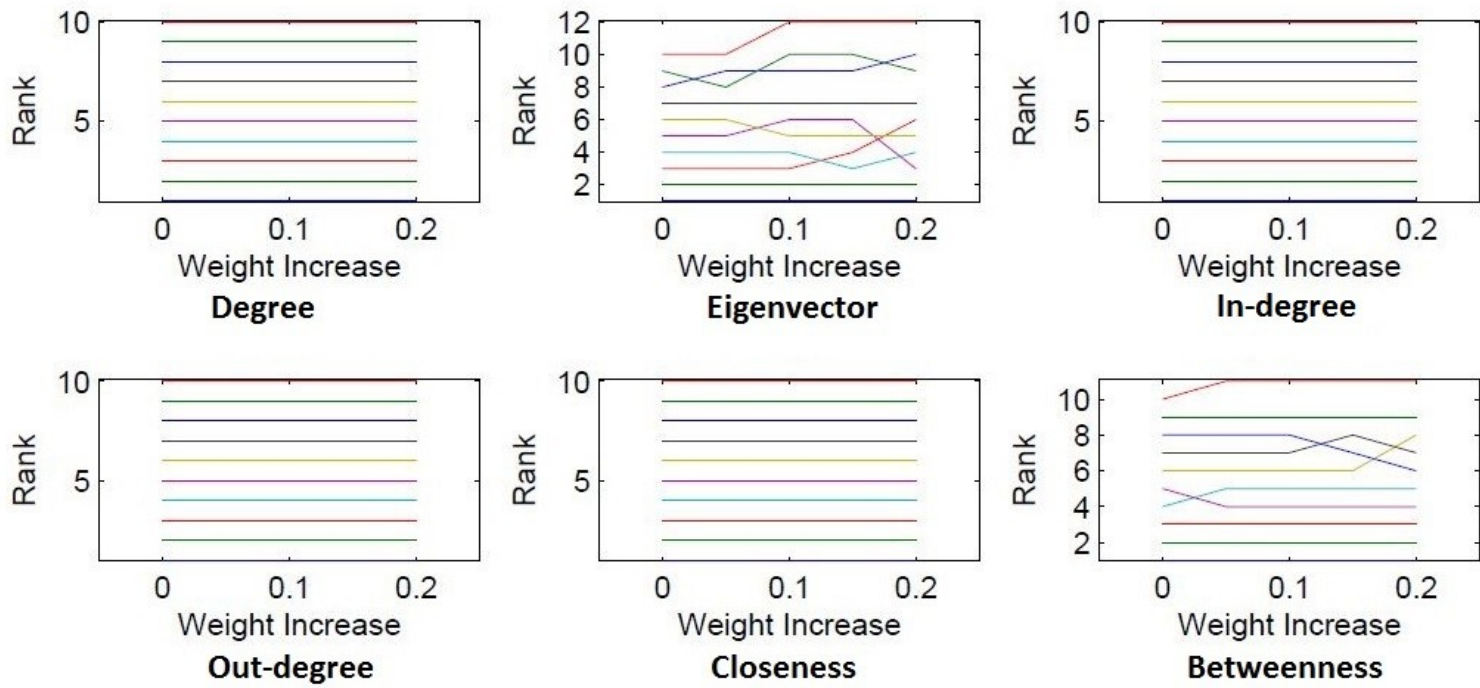

Figure 6: Change in node ranks with increase in criteria weights (line graph)
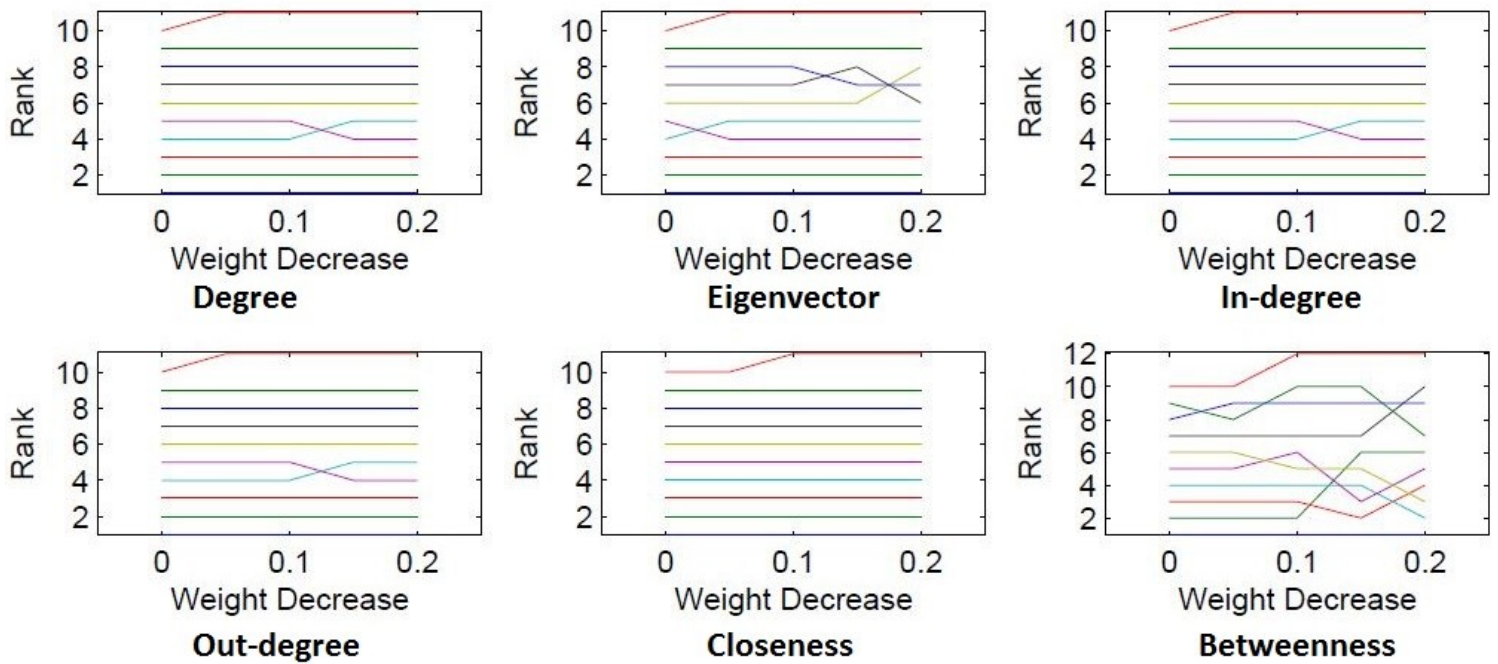

Figure 7: Change in node ranks with decrease in criteria weights (line graph)

The results of this analysis recognizes Betweenness as the most critical criterion in analysis, as it affect the ranking of nodes very quickly with respect to the changes (increase and decrease) in its decision weight. Other sensitive attribute is Eigenvector Centrality. It is essential to consider these sensitive criteria while making pairwise comparisons by decision makers.

\section{Future Scope}


The work can be further extended by using other individual attributes of these terrorist nodes with considered centrality measures, to achieve more insightful ranking. Several decision making units (DMUs) can be setup for dealing with subjective judgements and making pairwise comparison more robust.

\section{Conclusions}

SNA is one of the most effective investigative tool for studying various complex terrorist networks and organization. SNA Centrality Measures have been frequently used for identifying the key players and ranking of terrorists for various terrorist networks and activities. Analytical Hierarchy Process (AHP) can be combined with SNA centrality measures for obtaining enhanced rankings with the control of decision maker over subjective or objective choices for decision attributes.

In our work, we analyzed 9/11 terrorist network using proposed approach, for finding the rank ordering of all 63 terrorist nodes involved in the attack and identifying the key players among them. Evaluated ranking is based on the subjective judgments over considered six centrality measures as our decision criteria. Sensitivity analysis with trial and error method is applied for identifying the sensitive decision criteria. The experimental results exhibit that the amalgamation of AHP with SNA centrality measures results in propitious rank ordering in 9/11 terrorist network.

\section{Key References}

[1] Krebs, V. E. (2002). Mapping networks of terrorist cells. Connections, 24(3), 43-52.

[2] Freeman, L. C. (1978). Centrality in social networks conceptual clarification. Social networks, 1(3), 215-239.

[3] Choudhary, P., \& Singh, U. (2015). A Survey on Social Network Analysis for Counter-Terrorism. International Journal of Computer Applications, 112(9).

[4] Saaty, R. W. (1987). The analytic hierarchy process - what it is and how it is used. Mathematical Modelling, 9(3), 161-176.

[5] Saaty, T. L. (2000). Decision Making for Leaders; The Analytical Hierarchy Process for Decisions in a Complex World, Belmont, CA: Wadsworth. Pittsburgh: RWS Publications.

[6] Saaty, T. L. (2008). Decision making with the analytic hierarchy process. International journal of services sciences, 1(1), 83-98.

[7] Fox, W. P., \& Everton, S. F. (2014). Using data envelopment analysis and the analytical hierarchy process to find node influences in a social network. The Journal of Defense Modeling and Simulation: Applications, Methodology, Technology. 
ISAHP Article: A Style Guide for Paper Proposals To Be Submitted to the International Symposium on the Analytic Hierarchy Process 2016, London, U.K. 